\title{
A PARTICIPAÇÃO NORTE-AMERICANA NO TRÁFICO TRANSATLÂNTICO DE ESCRAVOS PARA OS ESTADOS UNIDOS, CUBA E BRASIL
}

\author{
The North American Involvement in the \\ Transatlantic Slave Trade to Brazil, Cuba, \\ and the United States of America \\ Leonardo Marques*
}

\begin{abstract}
RESUMO
O presente artigo explora as características do envolvimento norte-americano no tráfico transatlântico de escravos para Brasil, Cuba e Estados Unidos da América. Tal participação apresentou importantes transformações ao longo do século XIX, como resultado de crescentes tensões trazidas pela expansão de novas sensibilidades em relação ao tráfico transatlântico de escravos. Atenção especial é dada ao papel do estado de Rhode Island no tráfico e o impacto de legislações abolicionistas na comunidade de traficantes da região norte dos EUA.
\end{abstract}

Palavras-chave: tráfico negreiro; antiescravismo; abolição; história da América; Revolução Americana.

\begin{abstract}
The present article explores the characteristics of the North American involvement in the transatlantic slave trade to Brazil, Cuba, and the United States of America. The nature of this participation changed over the nineteenth century as a result of tensions brought by the rise of new sensibilities regarding the transatlantic slave trade. The article stresses the role played by the state of Rhode Island on the slave trade and the

"Doutorando em História pela Emory University. O presente artigo é composto de resultados preliminares de minha pesquisa de doutorado sobre a participação norte-americana no tráfico atlântico de escravos. Gostaria de agradecer a Carlos Alberto Medeiros Lima, David Eltis, Rafael Benthien, Martha Daison Hameister, Robert Desrochers, Daniel Domingues, Bruno Santos Alexandre e Tiago Luís Gil pela leitura do presente artigo ou versões anteriores do mesmo.
\end{abstract}


impact of abolitionist legislation on the slave trading community of the northern US.

Key-words: transatlantic slave trade; antislavery; abolition; history of the Americas; American Revolution.

Uma das principais consequências das sucessivas proibições do tráfico transatlântico de escravos ao longo do século XIX foi uma crescente internacionalização de suas operações. Em princípios da década de 1860, um enviado da Comissão Mista descrevia como os navios envolvidos no tráfico de escravos para Cuba eram comprados em Nova Iorque, carregavam uma tripulação com "homens de cada nação", eram capitaneados por cidadãos de New England e hasteavam a bandeira da Espanha ou dos Estados Unidos, de acordo com as circunstâncias. A participação de norte-americanos no tráfico ilegal para Cuba era evidente. Historiadores vêm encontrando norte-americanos envolvidos no tráfico ilegal não apenas para Cuba, mas para o Brasil e para os próprios Estados Unidos. Quais foram, no entanto, as características e extensão desse envolvimento ao longo de todo o período do tráfico ilegal? ${ }^{1}$

A historiografia acerca da participação dos EUA no trato negreiro é pequena se comparada aos estudos sobre escravidão no país. Isso se dá, em parte, pelo pequeno número de escravos transportados por americanos em comparação a portugueses, britânicos e franceses. Estima-se que navios com a bandeira dos Estados Unidos carregaram 305.326 africanos durante todo o período do tráfico transatlântico de escravos, o equivalente a pouco menos de 2,5\% das mais de doze milhões de almas transportadas através do Atlântico. Diversas leis restringindo e proibindo a participação de cidadãos dos EUA no tráfico foram passadas desde fins do século XVIII, como será discutido mais adiante ${ }^{2}$.

1 DRAKE, F. C.; SHUFELDT, R.W. Secret History of the Slave Trade to Cuba Written by an American Naval Officer, Robert Wilson Shufeldt, 1861. The Journal of Negro History, v. 55, n. 3, p. 218235, 1970. As Comissões Mistas foram tribunais internacionais fundados em acordos entre a Inglaterra e os principais países envolvidos no tráfico. Sobre o assunto, ver BETHELL, L. The Mixed Commissions for the Suppression of the Transatlantic Slave Trade in the Nineteenth Century. The Journal of African History, v. 7, n. 1, p. 79-93, 1966.

2 As estatísticas do tráfico utilizadas no presente artigo estão na Voyages: The Trans-Atlantic Slave Trade Database (www.slavevoyages.org). Parte dos dados sobre a participação de Rhode Island ainda estão em processo de atualização na base de dados como resultado de minha pesquisa. 
Ainda assim, o número de estudos sobre o envolvimento de norte-americanos no trato negreiro aumentou nos últimos anos. Ernest Obadele-Starks recentemente propôs uma reconsideração da força do tráfico transatlântico para os EUA após 1807 - ano em que o Congresso baniu o tráfico para o país -, argumentando que o mesmo foi fundamental para a persistência da escravidão até a Guerra Civil ${ }^{3}$. Gerald Horne expandiu a questão para o resto das Américas e argumentou que "cidadãos dos EUA eram líderes no incentivo ao tráfico ilegal, levando a uma transformação permanente do Brasil" ". Dale Graden também notou o envolvimento de norte-americanos no tráfico para o Brasil e concluiu que "milhares de cidadãos norte-americanos enriqueceram com o comércio negreiro". Segundo ele, "leis aprovadas nos Estados Unidos em 1794, 1800, 1808, 1819 e 1820 pouco serviram para desestimular o comércio transatlântico de escravos ao longo de sua costa leste. Empresários bem sucedidos assim como pessoas comuns participaram

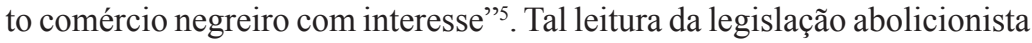
dos EUA como "letra morta," compartilhada pelos autores acima e outros, ecoa a visão exposta por W.E.B. Du Bois em seu clássico The Suppression of the Slave Trade to the United States of America ${ }^{6}$. Como discutido mais adiante, suas estimativas foram drasticamente reduzidas pela historiografia desde a década de 1960. Sua interpretação acerca da ineficácia das leis, no entanto, ainda persiste entre alguns historiadores.

Pesquisadores vêm se debruçando sobre as implicações da grande transformação na percepção moral que crescentemente questionou a legitimidade do sistema escravista a partir do século XVIII ${ }^{7}$. Pouco se sabe

3 OBADELE-STARKS, E. Freebooters and Smugglers: The Foreign Slave Trade in the United States after 1808. Fayetteville: University of Arkansas Press, 2007.

4 HORNE, G. The Deepest South: The United States, Brazil, and the African Slave Trade. New York: NYU Press, 2007, p. 34.

5 GRADEN, D. T. O envolvimento dos Estados Unidos no comércio transatlântico de escravos para o Brasil, 1840-1858. Afro-Ásia, v. 39, p. 33-34, 2007.

6 DU BOIS, W. E. B. The Suppression of the African Slave-Trade to the United States of America, 1638-1870. New York: Longmans, Green and Co., 1896.

7 Um importante debate surgiu acerca das origens de tal transformação. Para David Brion Davis, uma ideologia de trabalho livre tornou-se eficaz por acomodar-se ao ambiente político de uma Inglaterra marcada pelo crescimento industrial. Thomas Haskell criticou tal interpretação como sendo um refinamento "gramsciano" da tese inicial de Eric Williams, que por sua vez havia atribuído a abolição a um declínio econômico do sistema escravista. Para Haskell, a expansão internacional de mercados foi o fator fundamental no desenvolvimento de uma sensibilidade humanitária ao conectar indivíduos de diferentes 
acerca das dinâmicas sociais geradas por tal mudança. Em um dos poucos trabalhos explorando o impacto da emergência de uma nova sensibilidade no cotidiano de traficantes de escravos, Seymour Drescher demonstrou a crescente pressão isolando traficantes britânicos na cidade de Liverpool e, a partir de certo momento, no interior da mesma ${ }^{8}$. Tensões semelhantes emergiram no norte dos Estados Unidos e atravessaram o cotidiano de famílias envolvidas no tráfico. O caso mais famoso é certamente o dos irmãos Brown, de Providence, Rhode Island. Após algumas viagens no comércio negreiro, Moses Brown abandonou o negócio e envolveu-se em movimentos abolicionistas na segunda metade do século XVIII. Seu irmão John Brown, por outro lado, considerava o tráfico negreiro fundamental para a prosperidade econômica da região e tornou-se um ardoroso defensor do mesmo. Nas décadas que se seguiram, os dois irmãos protagonizaram debates e conflitos que se estenderam aos tribunais locais?.

O presente artigo explora as características do envolvimento norte-americano no tráfico Atlântico de escravos para Cuba, Brasil e Estados Unidos e sua transformação ao longo do século XIX. Tal mudança, a meu ver, foi um produto das tensões geradas pela transformação nas sensibilidades, transformação esta que se alastrou pelo Atlântico norte e passou a questionar a moralidade do tráfico negreiro. Após discutir as características gerais do tráfico e o impacto de leis antitráfico, concluo com uma discussão sobre a trajetória dos D'Wolf, a maior família de traficantes da história dos Estados Unidos. Mudando a escala de análise, é possível observar como os dois processos - a internacionalização do tráfico Atlântico e uma transformação nas sensibilidades em relação à escravidão - se articularam e influenciaram as atividades de traficantes norte-americanos.

partes do mundo e estabelecer um sentimento de "confiança" necessário às atividades comerciais. O debate, originalmente publicado no periódico American Historical Review, foi reeditado em BENDER, T. (Ed.). The Antislavery Debate: Capitalism and Abolitionism as a Problem in Historical Interpretation. Berkeley: University of California Press, 1992.

8 DRESCHER, S. Capitalism and abolition: values and forces in Britain, 1783-1814. In: ANSTEY, R.; HAIR, P. E. H. (Org.). Liverpool, the African Slave Trade, and Abolition: Essays to Rate Current Knowledge and Research. Liverpool: Historic Society of Lancashire and Cheshire, 1976.

90 caso se tornou popular após uma pesquisa realizada pela Brown University visando explorar os laços históricos da instituição com a escravidão. O relatório produzido pelo comitê de pesquisa da Universidade pode ser acessado em: <http://www.brown.edu/Research/Slavery_Justice/report/>. 


\section{A Revolução Americana e a primeira fase do tráfico ilegal}

O período entre 1783, quando a guerra de independência dos Estados Unidos chegou ao fim, e 1807, quando foi passada a proibição federal do tráfico de escravos no país, foi marcado pela intensa participação de cidadãos norte-americanos no tráfico atlântico de escravos. Nesse intervalo, comerciantes estadunidenses transportaram em torno de 165.000 escravos para as Américas, um número maior que o de todos os escravos carregados em navios norte-americanos entre 1645, quando o primeiro navio negreiro partiu das treze colônias, e 1776, quando eclodiu o movimento de independência. Parte considerável desses escravos, como veio a ser o caso para o Brasil meio século depois, foram transportados ilegalmente.

Rhode Island, a menor das treze colônias britânicas, foi o principal Estado envolvido no tráfico atlântico de escravos. Com um território de aproximadamente 4.000 quilômetros quadrados e condições climáticas pouco favoráveis à produção das principais mercadorias das zonas tropicais, o mar se tornou um recurso estratégico de sobrevivência para boa parte de seus habitantes. Além da pesca e do comércio, o Estado era o principal produtor de rum na América do Norte, utilizando cana-de-açúcar importada do Caribe. Tal relacionamento com o oceano resultou em um envolvimento intenso no comércio de escravos. A preponderância de negociantes de Rhode Island no tráfico de escravos, os maiores na história dos EUA, levou o historiador Jay Coughtry a afirmar que "a história do tráfico de escravos nos Estados Unidos é a história de Rhode Island" ". A assertiva de Coughtry é exagerada, mas próxima da verdade se considerarmos apenas o período após a independência e ignorarmos a breve, porém intensa, participação da Carolina do Sul. O principal fator determinando a competição foi a reabertura oficial do tráfico para a Carolina do Sul entre 1803 e 1807. Pouco se sabe acerca da organização deste setor do tráfico, mas há evidências de negociantes de Rhode Island também atuando e organizando viagens a partir de Charleston ${ }^{11}$.

10 COUGHTRY, J. The Notorious Triangle: Rhode Island and the African Slave Trade, 17001807. Philadelphia: Temple University Press, 1981, p. 25.

11 McMillin, J. A. The Final Victims: Foreign Slave Trade to North America, 1783-1810. Columbia, SC: University of South Carolina Press, 2004, p. 89. 
A entrada de estadunidenses no tráfico atlântico de escravos assumiu um caráter completamente distinto após o fim da guerra de independência, em 1783. O principal mercado explorado por traficantes norte-americanos até então havia sido o Caribe britânico, recebendo mais da metade dos escravos transportados entre 1645 e 1776 devido à alta demanda pelo braço escravo que acompanhou a expansão açucareira na região. Com a independência dos EUA, cortaram-se os laços comerciais entre a nova república e o Império Britânico, forçando negociantes norte-americanos a buscarem novos mercados ${ }^{12}$.

A Revolução Americana, por outro lado, liberou comerciantes das antigas restrições coloniais, estimulando o desenvolvimento de um eficiente comércio de longa distância ${ }^{13}$. $\mathrm{O}$ trato negreiro aumentou substancialmente nesse novo contexto. A eficiência de um mercado mais livre preconizada por Adam Smith pôde ser vista, paradoxalmente, na atividade de traficantes norte-americanos. Entre 1783 e 1807, tais negociantes desembarcaram escravos em diversos portos do Atlântico, de Providence a Montevidéu. Eis aqui outro aspecto inédito da participação norte-americana no tráfico atlântico de escravos: mais da metade dos escravos transportados foram desembarcados em portos fora dos Estados Unidos ${ }^{14}$.

Enquanto negociantes se aproveitavam da nova situação, movimentos abolicionistas na Inglaterra e no norte dos Estados Unidos passaram a denunciar o tráfico, mobilizando a opinião pública e acionando recursos legais contra traficantes. A oposição ao tráfico de escravos nos Estados Unidos precedeu a Revolução Americana, mas apenas em fins do século XVIII tal questão assumiu um caráter político nos níveis estadual e nacional ${ }^{15}$. O tema se tornou central com a reunião da Convenção Constitucional, em 1787. O resultado final dos debates na Convenção foi a nona seção do primeiro

12 KNIGHT, F. The American Revolution and the Caribbean. In: BERLIN, I.; HOFFMAN, R. (Orgs.). Slavery and Freedom in the Age of the American Revolution. Urbana: University of Illinois Press, 1986.

13 McCUSKER, J. J.; MENARD, R. The Economy of British America, 1607-1789. Columbia, SC: University of North Carolina Press, 1991. $866 \&$ flag $=5>$.

$14 \mathrm{Cf}$. <http://slavevoyages.org/tast/assessment/estimates.faces?yearFrom=1783\&yearTo=1

15 Em 1698, por exemplo, a Carolina do Sul já havia implementado uma legislação para estimular a imigração de trabalhadores brancos sob contrato já que "o grande número de escravos que vem sendo importado para esta colônia pode ameaçar a segurança da mesma”. Em 1717, assim como em 1740, após a Rebelião de Stono, taxas foram instituídas para diminuir a importação de africanos. 
artigo da Constituição dos Estados Unidos, limitando o poder do Congresso de regular o tráfico de escravos até 1808: “A migração ou importação de tantas pessoas quantas qualquer Estado ache conveniente permitir que entrem não deve ser proibida pelo Congresso antes do ano de mil oitocentos e oito, mas taxas e tarifas podem ser colocadas em tais importações, não excedendo o valor de dez dólares por pessoa" ${ }^{16}$. O artigo, de acordo com o historiador Don Fehrenbacher, "implicitamente confirmava o poder de regulamentação enquanto o suspendia até 1808 "17. Não havia, no entanto, qualquer referência ao tráfico norte-americano de escravos para territórios estrangeiros. A regulamentação limitava-se ao desembarque de cativos em portos norte-americanos.

Legislação proibindo qualquer participação no tráfico de escravos emergiu gradualmente no âmbito estadual. Em 1779, ainda durante a Guerra de Independência, Rhode Island proibiu a venda de escravos para fora da colônia. Em 1784, o Estado aprovou um ato abolindo gradualmente a escravidão e, em 1787, mesmo ano da Convenção Constitucional, proibiu a participação de cidadãos de Rhode Island no trato negreiro. Ela também se aplicava a qualquer "capitão, construtor, ou proprietário de qualquer embarcação, [que] direta ou indiretamente importar ou transportar, comprar ou vender, embarcar com intenção de importar e transportar de seus países de origem, qualquer um dos nativos habitantes de qualquer estado ou reino daquela parte do mundo conhecida como África, como escravos ou sem seu consentimento" ${ }^{18}$. Uma multa de cem libras foi instituída para cada escravo transportado e mil libras para cada embarcação envolvida no tráfico. Essa legislação teve um impacto imediato na comunidade de traficantes de Rhode Island. Em 1788, apenas quatro navios negreiros partiram em direção à África. O susto, no entanto, foi breve e em um curto espaço de tempo o número de viagens à África aumentou substancialmente.

O Congresso dos EUA ainda tinha o poder de limitar a participação no tráfico para outros países, apesar de impossibilitado de regulamentar a entrada de escravos nos portos do próprio país. Assim, em 1794, foi aprovado o Act to Prohibit the Carrying on the Slave Trade from the United

16 Constituição dos Estados Unidos da América, artigo 1, seção 9.

17 FEHRENBACHER, D. E. The Slaveholding Republic: an account of the United States government's relations to slavery. New York: Oxford University Press, 2001, p. 136.

18 DONNAN, E. Documents Illustrative of the History of the Slave Trade to America. Washington, D.C.: $1930-35$, v. 4, p. 344. 
States to Any Foreign Place or Country, tornando ilegal a participação de qualquer cidadão norte-americano, ou estrangeiro vivendo no país, no comércio negreiro para outras regiões, fosse como investidor ou capitão. A lei ainda especificava uma multa de dois mil dólares para qualquer embarcação envolvida com o tráfico que fosse capturada e de duzentos dólares para cada escravo a bordo. Em 1800, uma nova lei fortaleceu o Ato de 1794, permitindo a fiscalização de embarcações suspeitas por navios norte-americanos comissionados. Transgressores teriam que pagar uma multa equivalente ao dobro do valor investido no navio negreiro, podendo haver multas adicionais de até dois mil dólares e dois anos de prisão. Autoridades locais se esforçaram para fazer valer a legislação. Em 1800, dois navios escravos foram levados à Philadelphia e seus cativos liberados. Entre 1794 e 1804, mais de 20 processos legais foram iniciados contra traficantes de escravos de Rhode Island ${ }^{19}$.

O tráfico norte-americano, apesar de não ter se resumido a Rhode Island, teve seus padrões centrais definidos pelo Estado. Uma rede conectando Rhode Island, Costa do Ouro e Cuba marcou profundamente o comércio negreiro levado adiante por norte-americanos. Como mostra a Tabela 1, aproximadamente metade de todos os africanos comprados por negociantes de Rhode Island vieram de portos na Costa do Ouro. Serra Leoa forneceu aproximadamente $19 \%$ e a região Sudeste, composta principalmente pelos portos de Moçambique, forneceu em torno de $10 \%$ de escravos, reforçando a imagem de extrema mobilidade dos negociantes estadunidenses após a Revolução Americana.

A conexão entre Rhode Island, Costa do Ouro e Cuba ancorou-se em dois elementos. $\mathrm{O}$ acesso à região africana era facilitado pelo sistema de ventos e correntes do Atlântico Norte e pela notável produção de rum de Rhode Island (que, por outro lado, dependia do melaço cubano) ${ }^{20}$. Admi-

19 Uma boa síntese de toda a legislação antitráfico nos EUA pode ser encontrada em FINKELMAN, P. Regulating the African Slave Trade. Civil War History, v. 54, n. 4, 2008.

20 As ligações históricas no Atlântico Sul entre Bahia e o Golfo do Benin, bem como Rio de Janeiro e Angola, por outro lado, tiveram a presença crucial de mercadorias específicas. No primeiro caso, Pierre Verger mostrou há décadas o papel fundamental exercido pelo tabaco de baixa qualidade produzido no recôncavo baiano. O produto possibilitou a entrada de traficantes baianos em um território fortemente controlado por outros impérios europeus. No caso carioca, a geribita, um destilado produzido na América Portuguesa, teve papel semelhante. VERGER, P. Trade Relations between the Bight of Benin and Bahia from the $17^{\text {th }}$ to $19^{\text {th }}$ century. Ibadan, Nigeria: Ibadan University Press, 1976; FERREIRA, R. Dinâmica do 
TABELA 1 - REGIÕES DE EMBARQUE DE ESCRAVOS EM NAVIOS PROVENIENTES DE RHODE ISLAND

\begin{tabular}{l|c|c|c}
\hline Região de Embarque & Viagens & Escravos & $\%$ \\
\hline Costa do Ouro & 94 & 10611 & 49,94 \\
\hline Serra Leoa & 41 & 4022 & 18,93 \\
\hline Sudeste da África & 10 & 2059 & 9,69 \\
\hline Outros portos africanos & 12 & 1480 & 6,97 \\
\hline Windward Coast & 13 & 1357 & 6,39 \\
\hline Senegambia & 16 & 1028 & 4,84 \\
\hline África Central & 3 & 442 & 2,08 \\
\hline Golfo do Benin & 2 & 248 & 1,17 \\
\hline Total & 191 & 21248 & 100 \\
\hline
\end{tabular}

FONTE: cf. Figura 1.

nistradores britânicos na costa da África Ocidental mostravam-se ansiosos durante a Revolução Americana com o desaparecimento do rum de Rhode Island na região. Richard Miles, responsável pelo castelo em Cape Coast, Gana, reclamava que o rum importado do Caribe não era recebido com o mesmo entusiasmo por consumidores africanos. A popularidade do produto era tão grande que negociantes de Rhode Island ficaram famosos na costa africana como "homens-rum". "Africanos lembravam do rum americano muito bem", argumenta Jay Coughtry, "demandaram o mesmo quando reapareceu na costa e, consequentemente, forçaram os europeus a aceitarem, ao invés de impedirem, os homens-rum" ${ }^{21}$.

Nas Américas, traficantes de Rhode Island exploraram diversos mercados. Dois navios, o Louisiana e o Columbia, desembarcaram escravos em portos brasileiros em 1804 e 1807, respectivamente. De acordo com a documentação existente sobre o tráfico, no entanto, a conexão com o Brasil foi tênue, limitando-se às duas viagens. Apesar da grande diversidade de

comércio intracolonial: geribita, panos asiáticos e guerra no tráfico angolano de escravos. In: FRAGOSO, J.; BICALHO, M. F.; GOUVÊA, M. F. (Orgs.). O antigo regime nos trópicos: a dinâmica imperial portuguesa (séculos XVI-XVIII). Rio de Janeiro: Civilização Brasileira, 2001, p. 339-378; ALENCASTRO, L. F. de. $O$ Trato dos Viventes: formação do Brasil no Atlântico Sul, séculos XVI e XVII. São Paulo: Companhia das Letras, 2002.

21 COUGHTRY, J. Op. cit., p. 114. 
mercados consumidores característica da participação norte-americana no tráfico, Cuba cristalizou-se como o principal deles para negociantes de Rhode Island. A ilha ocupou um lugar estratégico em termos militares e comerciais no Império Espanhol ao longo de sua história, mas até meados do século XVIII sua produção agrícola limitou-se a pequenas quantidades de tabaco, com a utilização de poucos escravos. Em torno da década de 1750 , a produção açucareira na ilha aumentou, mas com números muito abaixo das vizinhas ilhas francesas e britânicas. Tal situação começou a se transformar com a Guerra dos Sete Anos e a ocupação britânica de Havana, em 1762. Com a retomada do território pelos espanhóis, a ilha emergiu como um ponto privilegiado para experimentos de reforma imperial. As reformas bourbônicas gradualmente eliminaram algumas das mais importantes restrições comerciais da ilha, sendo as duas cédulas de 1789 e 1791 partes importantes nessa transformação. Os documentos aboliram taxas de importação e preços rígidos, estimulando a aproximação de negociantes estrangeiros. "O efeito", argumenta David Eltis, "foi integrar Cuba no mercado caribenho de escravos e reduzir a diferença de preços entre escravos cubanos e não cubanos" ${ }^{\prime 2}$.

Durante o mesmo período, a famosa rebelião de escravos que levou ao fim da colônia francesa de Saint-Domingue, até então a maior produtora de açúcar e café do Ocidente, aumentava as oportunidades de entrada no mercado mundial para Cuba. Tal condição favorável foi fortalecida ainda mais com a abolição do tráfico transatlântico de escravos no Império Britânico em 1807, que, por sua vez, diminuiu as chances de que o Caribe britânico voltasse a ocupar sua posição hegemônica na produção de açúcar anterior à ascensão de Saint-Domingue. A colônia espanhola emergia, assim, como o principal reduto escravista do Caribe nas primeiras décadas do século XIX. Franceses refugiados da revolução em Saint-Domingue perceberam rapidamente as possibilidades oferecidas por Cuba, dando início a novas plantações de açúcar e café. Oito dos dez maiores engenhos de açúcar na colônia espanhola em 1804 foram construídos por imigrantes franceses ${ }^{23}$. Em 1807, mais de cem fazendas eram de propriedade francesa, com mais de

22 ELTIS, D. Economic Growth and the Ending of the Transatlantic Slave Trade. New York: Oxford University Press, 1987, p. 36.

23 FRAGINALS, M. M. O Engenho. v. I, II e III. Coleção Estudos Históricos. São Paulo: Editora UNESP/HUCITEC, 1988. 
3.000 escravos distribuídos entre elas ${ }^{24}$. O número de plantations aumentou vertiginosamente na virada do século, bem como o de africanos importados para a ilha. Entre 1800 e 1830, estima-se que em torno de 347.640 foram desembarcados na colônia espanhola, um número cinco vezes maior que o total de cativos importados durante toda a história de Cuba anterior ao século XIX ${ }^{25}$.

A ilha tornava-se um mercado promissor para traficantes norte-americanos que, como visto, possuíam vínculos históricos com a região. As relações desses traficantes com Cuba, bem como com outros comerciantes importantes da região de New England, iam além do trato negreiro. Negociantes de Rhode Island, Boston e outros estados ao norte dos EUA perceberam as oportunidades e, como vinham fazendo refugiados de Saint-Domingue, investiram em fazendas de café e açúcar na colônia espanhola. Norte-americanos possuíam pelo menos cinquenta fazendas de café e açúcar em 1823, avaliadas em torno de três milhões de dólares ${ }^{26}$. Diversos viajantes americanos e ingleses em Cuba notaram a existência destas imensas propriedades nas mãos de migrantes do norte. $\mathrm{O}$ fácil e barato acesso a escravos na colônia espanhola, bem como a relação histórica entre a produção de melaço cubano e rum de Rhode Island, provavelmente tiveram influência no surgimento de tais fazendas. Alguns desses negociantes estiveram envolvidos desde o século XVIII no tráfico de escravos para a ilha, acompanhando de perto seu crescimento e as possibilidades que se abriam ${ }^{27}$.

24 DEBIÉN, G. The Saint-Domingue Refugees in Cuba, 1793-1815. In: BRASSEAUX, C. A.; CONRAD, G. R. (Orgs.). The Road to Louisiana: The Saint-Domingue Refugees 1792-1809. Lafayette: University of Southwestern Louisiana, 1992.

$25<\mathrm{http} / / /$ slavevoyages.org/tast/assessment/estimates.faces?yearFrom $=1500 \&$ yearTo $=1830$ \&disembarkation $=701>$.

26 PEREZ JR., L. A. Cuba and the United States: Ties of Singular Intimacy. Athens: University of Georgia Press, 1988, p. 24.

27 Nas décadas que se seguiram, os laços entre norte-americanos e Cuba tornaram-se mais fortes. Em meados do século XIX, negociantes estadunidenses estavam envolvidos em diversos setores da economia Cubana. Casas comerciais norte-americanas operavam nos principais portos, estabelecendo transações comerciais de importação e exportação e providenciando crédito para fazendeiros locais. A primeira estrada ferroviária da América Latina, a linha Havana-Guines, foi desenvolvida por engenheiros norte-americanos e utilizou equipamentos e suprimentos do vizinho do norte. Em 1846, aproximadamente 1.256 estadunidenses viviam na ilha, número que subiu para $2.500 \mathrm{em} 1862$. Conforme argumenta Louis Perez, a presença norte-americana na ilha era pequena, mas ocupava setores estratégicos da economia. Ibidem, p. 17-24. 
FIGURA 1 - PORCENTAGEM DE ESCRAVOS DESEMBARCADOS EM CUBA POR NACIONALIDADE DOS TRAFICANTES, 1790-1807

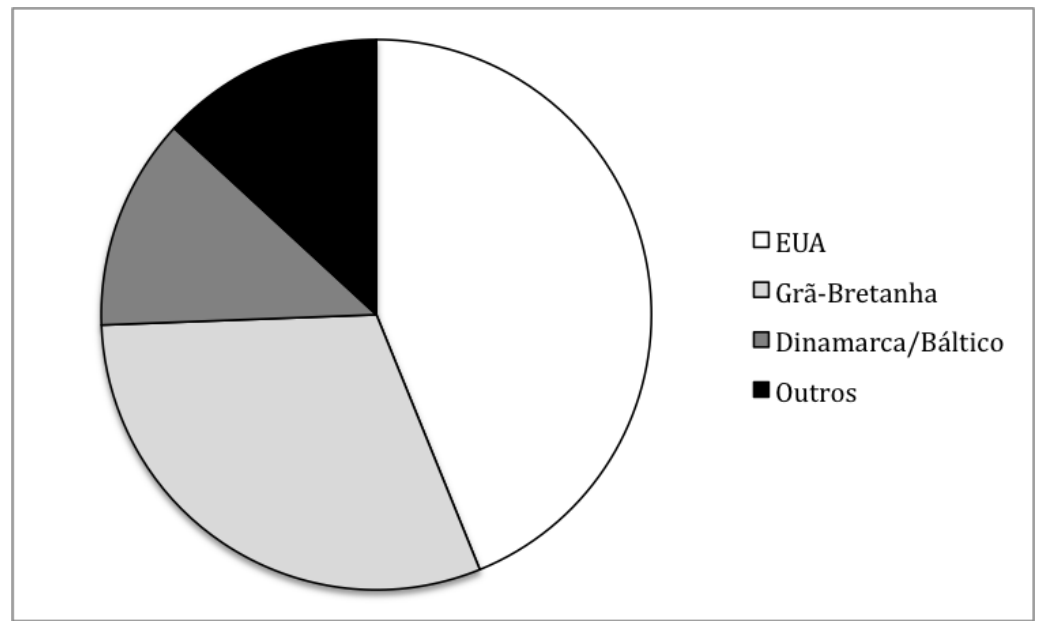

FONTE: Voyages: The Trans-Atlantic Slave Trade Database (disponível em: <http://www.slavevoyages. org $>$ ).

Uma pesquisa na base de dados Voyages demonstra que a maioria das viagens norte-americanas que desembarcaram escravos em Cuba partiu de Rhode Island ${ }^{28}$. As viagens organizadas a partir da Carolina do Sul tinham o objetivo específico de abastecer os portos daquele Estado ${ }^{29}$. O período de reabertura do tráfico para os portos da Carolina do Sul foi o principal evento a alterar o predomínio da rede conectando Rhode Island, Costa do Ouro e Cuba. Entre 1803 e 1807, 40.000 escravos foram introduzidos no Estado, um número que tendia a crescer com a explosão da produção de algodão no sul dos EUA. Do lado cubano, o suprimento de escravos em fins do XVIII era extremamente dependente das atividades de traficantes norte-americanos e britânicos. Entre 1790 e 1807, os dois grupos foram responsáveis por aproximadamente 75 por cento de todos os escravos desembarcados na ilha (Figura 1).

$28<\mathrm{http}: / /$ slavevoyages.org/tast/database/search.faces?yearFrom=1783\&yearTo=1807\&nati nimp $=9$ \&ptdepimp $=20100>$.

$29<$ http://slavevoyages.org/tast/database/search.faces?yearFrom=1783\&yearTo=1807\&nati nimp $=9 \&$ ptdepimp $=21300>$. 


\section{As leis antitráfico do século XIX}

De acordo com a Constituição dos Estados Unidos, o ano de 1807 marcaria a volta do poder do Congresso em regular o tráfico transatlântico de escravos. Em março daquele ano, o Parlamento do Reino Unido já havia passado o "A to pela Abolição do Tráfico de Escravos", abolindo o comércio negreiro nos territórios britânicos e a participação de seus cidadãos no tráfico para outras regiões. Com toda a regulamentação que já vinha sendo colocada em prática em diversos estados norte-americanos nas décadas anteriores, a aprovação da lei proibindo definitivamente a importação de escravos africanos pelas duas casas do Congresso dos EUA não foi nenhuma surpresa. A partir do dia primeiro de janeiro de 1808, estava proibido "importar ou trazer para os Estados Unidos ou para territórios de qualquer reino estrangeiro, ou país, qualquer negro, mulato ou pessoa de cor, com a intenção de manter, vender ou transferir tal negro, mulato ou pessoa de cor como escrava, ou para ser obrigada a prestar serviços ou trabalhar". Dividido em dez seções, o ato de 1807 proibia o envolvimento de cidadãos estadunidenses no tráfico de escravos em todos os níveis e para qualquer território. As penas eram variadas e atingiam desde compradores de escravos, que deveriam pagar uma multa de 800 dólares para cada escravo comprado, a construtores de navios para o tráfico, cujas multas poderiam chegar a 20.000 dólares $^{30}$.

Para W. E. B. Du Bois, como mencionado anteriormente, a lei de 1807 foi quase letra morta. Segundo ele, traficantes carregaram em torno de 250.000 escravos para os Estados Unidos entre 1807 e a Guerra Civil. Outros pesquisadores da primeira metade do século XX, como Winfield Collins e Lewis Gray, chegaram a estimativas parecidas. Nas décadas que se seguiram, no entanto, diversos historiadores e economistas, como Philip Curtin, Robert Fogel e Stanley Engerman, reduziram tais estimativas significativamente. Um dos principais problemas nos números altos apresentados por Du Bois decorria de sua confusão entre o tráfico conduzido para os EUA e para outros territórios, como Cuba e Brasil. Estudos atuais defendendo estimativas mais

30 "An Act to prohibit the importation of slaves into any port or place within the jurisdiction of the United States, from and after the first day of January, in the year of our Lord one thousand eight hundred and eight". $9^{\text {th }}$ Cong., 2d Sess., Act of Mar. 2, 1807, Chap. 22, 2 Stat 426. 
altas, como o trabalho de Ernest Starks, sofrem do mesmo problema ${ }^{31}$. A estimativa mais recente e confiável acerca do número de escravos traficados para o território norte-americano durante o período ilegal foi oferecida por David Eltis, que na verdade não se distancia muito dos números de Fogel e Engerman. Eltis sugere que em torno de 52.000 escravos foram trazidos para o território norte-americano após a abolição, sendo apenas 6.100 desses transportados diretamente da África. A maior parte de cativos trazidos para os Estados Unidos vieram de outras partes das Américas ${ }^{32}$.

Os atos abolindo o tráfico na Inglaterra e nos EUA em 1807, portanto, tornavam ilegais as atividades dos principais abastecedores de escravos para Cuba e Estados Unidos. O resultado no último foi a emergência de um tráfico interno carregando escravos de áreas mais antigas, como Virginia e Maryland, para territórios à oeste, engajados na produção de algodão. Que tal movimentação tenha ocorrido atesta, inclusive, a eficiência da lei abolindo a entrada de escravos a partir de 1808. É importante lembrar que, antes de 1807, diversas outras leis federais e estaduais proibindo a participação de cidadãos norte-americanos no tráfico transatlântico já estavam em vigor. Os vínculos de traficantes com Cuba se desenvolveram ilegalmente durante aquelas décadas.

A eficácia da lei de 1807 em proibir a participação de cidadãos norte-americanos no tráfico de escravos para outros países é um tema ainda aberto a especulações. A questão assumiu um caráter internacional entre as autoridades abolicionistas da época. Após a abolição do tráfico de escravos no Império Britânico, autoridades notaram que mercadores, embarcações e portos ingleses continuavam a ocupar um papel importante no trato negreiro. As atividades de abolicionistas britânicos nesses anos iniciais visavam impedir o envolvimento de seus cidadãos no tráfico e impedir a entrada de escravos em seus domínios. Tratados internacionais com os principais impérios e países envolvidos no tráfico de escravos foram elaborados. $\mathrm{O}$ conhecido Tratado de Amizade e Aliança entre Inglaterra e Portugal, de

31 Obadele-Starks sugere que o número de escravos trazidos para os EUA durante o período pode ter chegado a 786.500. A explicação oferecida pelo autor para tal estimativa é, para dizer o mínimo, incompleta. OBADELE- STARKS, E. Op. cit., p. 10.

32 Uma ótima síntese da discussão dos números do tráfico ilegal para os EUA pode ser encontrada no apêndice de DIOUF, S. A. Drams of Africa in Alabama: the slave ship Clotilda and the story of the last Africans brought to America. New York: Oxford University Press, 2007, p. 241-243. As estimativas de Eltis estão em ELTIS, D. The US Trans-Atlantic Slave Trade, p. 353. 
1810, restringia, em sua décima cláusula, os limites geográficos do tráfico negreiro carregado por portugueses. A intenção era evitar que traficantes portugueses ocupassem espaços deixados pela saída de britânicos e americanos. Outros tratados foram estabelecidos nas décadas que se seguiram entre Inglaterra, Portugal e Brasil. O tráfico para o Brasil chegou ao fim apenas na década de $1850^{33}$.

Autoridades britânicas acreditavam que o tráfico de escravos operado sob a bandeira espanhola era na verdade carregado por americanos e britânicos. Consequentemente, na primeira década após a abolição no Império Britânico, não houve qualquer acordo entre os governos britânico e espanhol. Autoridades britânicas, no entanto, apreenderam diversos navios espanhóis envolvidos no tráfico suspeitos de serem de propriedade inglesa ou norte-americana. Um número crescente de reclamações de comerciantes espanhóis chegava às autoridades britânicas e um acordo foi finalmente estabelecido em 1817. Como no caso português/brasileiro, a ineficiência de tal tratado levou à elaboração de novos acordos nas décadas seguintes. O tráfico para Cuba seria suprimido definitivamente apenas em $1866^{34}$.

Os Estados Unidos não estabeleceram nenhum tipo de tratado com a Inglaterra autorizando o direito mútuo de busca em navios suspeitos até 1862, quando, no contexto da Guerra Civil, Abraham Lincoln estabeleceu o Tratado Lyons-Seward. Antes disso, os Estados Unidos eram os únicos autorizados a apreenderem navios de comerciantes norte-americanos suspeitos de envolvimento no tráfico. Em 1819, um estatuto nos EUA autorizou o envio de frotas armadas norte-americanas para policiar a costa do país e da África Ocidental. Em 1842, foi oficializada a criação do African Squadron, um setor da marinha norte-americana destinado a combater o tráfico ilegal de escravos. De tamanho extremamente reduzido, o esquadrão é normalmente encarado como um fracasso. Os poucos traficantes capturados em portos do Sul eram normalmente julgados por juízes simpáticos à escravidão, com a única condenação por pirataria ocorrendo apenas na década de $1860^{35}$.

33 Sobre o assunto, ver BETHELL, L. The Abolition of the Brazilian Slave Trade; Britain, Brazil and the Trade Question, 1807-1869. Cambridge (Eng.): University Press, 1970 e MARQUES, J. P. The Sounds of Silence: Nineteenth Century Portugal and the Abolition of the Slave Trade. New York: Berghahn Books, 2006.

34 MURRAY, D. R. Odious Commerce: Britain, Spain, and the Abolition of the Cuban Trade. Cambridge (Eng.): Cambridge University Press, 1980.

35 Ibidem, p. 305. 
A atuação discreta do African Squadron, a negligência de autoridades sulistas e a corrupção de diplomatas norte-americanos são alguns dos elementos que motivam especulações da historiografia acerca de uma entrada substancial de escravos nos EUA após a abolição do tráfico, bem como do envolvimento de cidadãos do país no tráfico de escravos para Cuba e Brasil. O já citado trabalho de Gerald Horne, por exemplo, baseia-se em evidências episódicas, como declarações de autoridades abolicionistas e diplomáticas. Horne usa um texto do jurista Joseph Story que, em 1852, "apontou o papel central de cidadãos estadunidenses para o tráfico de escravos africanos". Story relatou que "cidadãos americanos estão envolvidos até o último fio de cabelo (e isso não é exagero) nesta rede de injustiças [...] [eles] lotam a costa da África sob as bandeiras maculadas da Espanha e Portugal, por vezes vendendo seus carregamentos do desespero e às vezes trazendo-os aos portos sulistas... eu gostaria de poder dizer que New England e homens de New England estão isentos de toda essa sujeira". Gostaria, mas não podia, completa Horne ${ }^{36}$. Quais evidências existem, no entanto, sobre a participação de New England ou norte-americanos em geral no tráfico atlântico de escravos em meados do século XIX, quando a bandeira do país volta a ser utilizada por diversos traficantes?

Há, na verdade, um sumiço de norte-americanos entre donos de navios escravos até o reaparecimento da bandeira norte-americana no tráfico atlântico na década de 1840. Nesse intervalo, o tráfico para Cuba, que até 1810 havia sido dominado por norte-americanos e britânicos, passou principalmente para espanhóis e, em menor número, franceses. É importante observar que entre 1808 e 1820 não há evidência de qualquer traficante norte-americano desembarcando cativos no Brasil. Além de alguns desembarques em outras ilhas do Caribe, como Barbados e Dominica, a maior parte dos escravos transportados por norte-americanos durantes esses anos foi para Cuba e EUA ${ }^{37}$.

Um dos elementos que pode ter contribuído para a saída de traficantes norte-americanos ao fim da década de 1810 foi o "ato em adição aos atos proibindo o tráfico de escravos" de $1819^{38}$. O ato instituiu recompensas

36 HORNE, G. Op. cit., p. 33-34.

$37<\mathrm{http}$ ://slavevoyages.org/tast/assessment/estimates.faces?yearFrom=1808\&yearTo=1820 \&flag $=5>$.

38 "An Act in addition to the Acts prohibiting the slave trade", Act of Mar. 3, 1819, Chap. 101, 3 Stat. 532. 
para marinheiros, então autorizados a capturarem qualquer navio escravo na Costa da África e retornarem os escravos para o continente de origem dos mesmos. O governo dos EUA pagaria 25 dólares por escravo resgatado, a serem divididos entre a tripulação do navio captor, e 50 dólares por escravo resgatado para informantes cujas denúncias levassem à interceptação de navios negreiros. A lei de 1807 deixava para o âmbito estadual o destino dos escravos capturados em navios envolvidos no tráfico ilegal, sendo muitos vendidos em leilões e continuando sob cativeiro. Em 1820, outro ato declarou a participação de qualquer cidadão americano no tráfico atlântico como ato de pirataria e, portanto, passível de pena capital ${ }^{39}$.

De acordo com Paul Finkelman, os atos de 1819 e 1820 foram fundamentais ao focarem na injustiça de escravizar indivíduos que deveriam ser considerados livres. A associação da participação no tráfico ilegal à pirataria foi a atitude mais radical em relação à escravidão tomada pelo governo dos EUA até então. Sem dúvida a aplicação da lei foi deficiente. Em toda a história do tráfico ilegal, apenas um norte-americano foi condenado sob o ato de 1820, sendo enforcado em 1862 durante o governo de Abraham Lincoln ${ }^{40}$. A ausência de recursos, combinada à negligência de autoridades locais nos estados escravistas do sul, dificultava a imposição da lei. Mesmo não condenando ninguém à morte durante a maior parte do tempo em que esteve em vigor, a lei teve algum efeito ao tornar as operações mais caras e os riscos maiores ${ }^{41}$.

Se a lei de 1807 , portanto, já havia afastado muitos comerciantes do trato negreiro, os atos de 1819 e 1820 estimularam ainda mais a debandada. A bandeira dos EUA seria hasteada em navios negreiros novamente apenas duas décadas mais tarde. Mas a participação no tráfico assumiu características muito distintas. É importante notar que o tráfico ilegal até 1820 tinha norte-americanos em todos os aspectos das empreitadas, da organização ao financiamento. Na documentação existente para esse período, a maioria absoluta dos donos de embarcações com escravos partindo dos EUA tem nomes de origem anglo-saxônica, como William Boyd, Thomas

39 "An Act to continue in force... 'An act to protect the commerce of the United States and to punish the crime of piracy..." Act of May 15, 1820, Chap. 113, 3 Stat. 600.

40 SOODALTER, R. Hanging Captain Gordon: the life and trial of an American slave trade. New York: Atria Books, 2006.

41 FINKELMAN, P. Op. cit., p. 303-304. 
Martin, James Doodley, David Slocum e outros ${ }^{42}$. A bandeira utilizada normalmente coincidia com a nacionalidade dos donos e investidores das viagens do tráfico negreiro, uma situação que mudou já nos primeiros anos após a abolição nos Estados Unidos e Inglaterra, mas que alcançou níveis inéditos duas décadas mais tarde.

Quando analisamos os documentos das embarcações que partiram de portos norte-americanos usando a bandeira dos Estados Unidos, fica clara a desconexão entre as atividades de meados do XIX e as redes que carregaram o tráfico até fins da década de 1810. A rede de traficantes de Rhode Island, que dominou o tráfico após a independência do país, desaparece dos documentos de viagens negreiras após 1820. O único estado em toda a região de New England do qual partiram navios negreiros após 1840 foi Massachusetts. A maioria das viagens de que se tem evidência concreta neste período foi organizada a partir de Nova Iorque e New Orleans. Os dois estados foram responsáveis por $75 \%$ de todos os escravos desembarcados por navios que partiram de portos norte-americanos entre 1844 e o fim do tráfico atlântico em $1867^{43}$.

No lado africano, a antiga rede conectando norte-americanos à Costa do Ouro e, especialmente, Serra Leoa ainda mantinha certa força até fins da década de 1820. Quando navios negreiros voltaram a partir dos Estados Unidos em princípios da década de 1840, Serra Leoa, Senegambia, Golfo de Biafra e Golfo da Guiné deixaram de ser regiões de embarque de escravos. O foco passou a ser a África Central, mais precisamente Angola (Tabela 2). Na década de 1850, houve um aumento sensível nas importações de escravos em navios norte-americanos. Não por acaso, foi justamente nesse período que o tráfico de escravos para o Brasil chegou ao fim, com muitos traficantes brasileiros e portugueses redirecionando suas atividades para a ilha de Cuba, como discutido mais adiante.

Apesar da constante presença da bandeira norte-americana em navios negreiros após a década de 1830, o tráfico norte-americano assumiu um caráter menos direto. Bandeira, embarcações, tripulações e documentos norte-americanos foram fundamentais para o sucesso dessas operações. natinimp $=9>$.

42 Cf. $<$ http://slavevoyages.org/tast/database/search.faces?yearFrom=1808\&yearTo=1820\&

43 Cf. $<$ http://slavevoyages.org/tast/database/search.faces?yearFrom=1807\&yearTo=1866\& ptdepimp $=20000>$. 
TABELA 2 - NÚMERO DE ESCRAVOS DESEMBARCADOS NAS AMÉRICAS DIVIDIDOS POR REGIÃO DE EMBARQUE, 1808-1863

\begin{tabular}{c|c|c|c|c|c|c|c|c}
\hline & $\mathbf{1}$ & $\mathbf{2}$ & $\mathbf{3}$ & $\mathbf{4}$ & $\mathbf{5}$ & $\mathbf{6}$ & $\mathbf{7}$ & Total \\
\hline $\mathbf{1 8 0 8 - 1 8 1 0}$ & 218 & 815 & & 267 & 466 & 180 & 202 & 2148 \\
\hline $\mathbf{1 8 1 1 - 1 8 2 0}$ & 67 & 482 & & 75 & 1104 & & & 1728 \\
\hline $\mathbf{1 8 4 1 - 1 8 5 0}$ & & & & & 1359 & 430 & & 1789 \\
\hline $\mathbf{1 8 5 1 - 1 8 6 0}$ & & & 2363 & & 21682 & 1000 & & 25045 \\
\hline $\mathbf{1 8 6 1 - 1 8 6 3}$ & & & & & 4041 & & & 4041 \\
\hline Totais & 285 & 1297 & 2363 & 342 & 28652 & 1610 & 202 & 34751 \\
\hline$\%$ & 0,8 & 3,7 & 6,8 & 1,0 & 82,4 & 4,6 & 0,6 & 100 \\
\hline
\end{tabular}

1. Senegambia e região; 2. Serra Leoa; 3. Golfo do Benin; 4. Golfo de Biafra e Guiné; 5. África Central; 6. Sudeste da África e ilhas do Pacífico; 7. Outros.

FONTE: cf. figura 1.

Embarcações utilizadas no tráfico eram construídas em cidades norte-americanas como Baltimore enquanto comerciantes norte-americanos e britânicos forneciam produtos a crédito para traficantes. Também há evidência de capitães e tripulantes do país envolvidos no tráfico, bem como diplomatas facilitando os trâmites burocráticos para que documentos fossem emitidos e utilizados por traficantes espanhóis, portugueses e brasileiros. Entre 1835 e 1850, a maior parte das viagens usando a bandeira dos EUA partiu de Cuba e, especialmente, do Brasil. Das 88 viagens com a bandeira dos EUA que se tem evidência para estes anos, apenas quatro começaram em portos americanos: três em New Orleans e uma em Nova Iorque. A evidência de financiamento direto de traficantes norte-americanos nesse período é escassa. Apenas um dono de navio, Robert Bell, tem um nome claramente de origem anglo-saxônica, responsável pelo desembarque de 400 escravos no Rio de Janeiro em $1848^{44}$. Todos os outros donos de navios presentes na documentação possuíam sobrenomes espanhóis ou portugueses, sendo o maior deles Manoel Pinto da Fonseca. A presença de capitães americanos, por outro lado, parece ter sido comum em viagens com a bandeira dos EUA ${ }^{45}$. yageid $=3765>$.

$44<\mathrm{http}$ //slavevoyages.org/tast/database/search.faces?yearFrom=1514\&yearTo=1866\&vo $45<\mathrm{http}$ //slavevoyages.org/tast/database/search.faces?yearFrom=1830\&yearTo=1850\&nat inimp $=9>$. 
Dois exemplos famosos do investimento direto de norte-americanos no tráfico são as viagens dos navios Clotilda e Wanderer. A principal figura por trás da viagem do Clotilda era Timothy Meaher, um sulista envolvido nos debates para a reabertura do tráfico atlântico de escravos para o sul dos Estados Unidos. Sua participação no tráfico foi pontual. Assim também foi o caso de Charles Augustus Lafayette Lamar, um jovem e rico sulista de Savannah, que procurou demonstrar aos abolicionistas do norte do país a legitimidade da escravidão ao importar africanos com seu navio negreiro Wanderer. Lamar foi capturado por autoridades federais e julgado no Estado da Georgia. Sendo considerado inocente, diversos jornais sulistas divulgaram o caso e nos meses que se seguiram noticiaram vários desembarques de escravos, motivados pelo aumento das hostilidades e tensões seccionais ${ }^{46}$. $\mathrm{O}$ volume dessa participação no tráfico, no entanto, parece ter sido muito menor do que alardearam os jornais do período, fosse entre abolicionistas denunciando tais práticas ou sulistas afirmando seu poder ${ }^{47}$.

Após 1850 , portos norte-americanos também se tornaram muito mais presentes no tráfico transatlântico. Das 110 viagens realizadas com a bandeira dos Estados Unidos entre 1850 e 1866 e em que se sabe o porto de partida, 40 tiveram início em Nova Iorque e $13 \mathrm{em}$ New Orleans. Havana era o segundo porto mais importante, com 28 viagens. O território dos EUA passou a ter maior importância geográfica enquanto espaço de organização de viagens escravas no estágio final do tráfico ilegal. Com a lei abolindo o tráfico de escravos para o Brasil, em 1850, diversos traficantes portugueses e brasileiros transferiram suas atividades para o tráfico cubano, estabelecendo novas bases em Lisboa, Nova Iorque e na própria colônia espanhola. A base norte-americana foi a de maior sucesso. O traficante Cunha Reis, por exemplo, estabeleceu conexões com figuras importantes, como César Figanière, cônsul de Portugal em Nova Iorque, e seu irmão William. César facilitava as atividades do grupo enquanto William, naturalizado norte-americano, comprava e operava navios com registros do país ${ }^{48}$. Emilio Sanchez y Dolz, um

46 Sobre o Wanderer, cf. WELLES, T. H. The Slave Ship Wanderer. Athens: Univ. of Georgia Press, 1967.

47 DIOUF, S. Op. cit., p. 7-29.

48 CLARENCE-SMITH, G. The Third Portuguese Empire: A study in Economic Imperialism. Manchester. Manchester University Press, 1985, p. 71. Mais especificamente acerca da migração de portugueses e brasileiros para o tráfico cubano, ver CLARENCE-SMITH, G. The Portuguese Contribution to the Cuban Slave and Coolie Trades in the Nineteenth Century. Slavery \& Abolition, v. 5, 1984, e FERREIRA, R. 
traficante cubano naturalizado americano a serviço dos britânicos, sugeriu que o grupo português teria sido responsável por $40 \%$ das viagens escravas que partiram de Nova Iorque em $1859^{49}$. Independentemente das atividades da Companhia, os donos de navios partindo de Nova Iorque nesse período final do tráfico eram, via de regra, portugueses ou espanhóis ${ }^{50}$. É importante lembrar, também, que a porcentagem da participação dos traficantes de Nova Iorque no total de escravos transportados para Cuba durante esse período foi muito pequena. De acordo com David Eltis, "o centro de controle e a fonte de todo o capital para o tráfico cubano era a própria Cuba" ${ }^{51}$.

Evidências de americanos financiando diretamente o tráfico diminuíram dramaticamente após 1807 , mas há indicações de uma pequena parcela de investidores dos EUA até 1820. Nas décadas que se seguiram, a participação no tráfico passou a ser muito mais indireta, na forma de navios, documentos, bandeira e tripulantes.

\section{Traficantes ilhados}

A família D'Wolf, de Rhode Island, teve entre seus membros os maiores traficantes da história dos Estados Unidos, sendo responsáveis pelo transporte de aproximadamente 10.000 africanos para as Américas. O comércio de escravos operado pela família refletia os padrões mais gerais da participação de Rhode Island, com Cuba sendo o principal destino dos africanos transportados. A predominância cubana, como foi o caso para toda a participação norte-americana no tráfico, mudou apenas durante o período de reabertura do tráfico para a Carolina do Sul, no qual os D'Wolf também estiveram presentes. $\mathrm{O}$ envolvimento da família começou ainda na primeira metade do século XVIII, quando Mark Anthony D'Wolf, então

\footnotetext{
A. Dos sertões ao Atlântico: tráfico ilegal de escravos e comércio lícito em Angola, 1830-1860. Dissertação (Mestrado) - Universidade Federal do Rio de Janeiro - Instituto de Filosofia e Ciências Sociais, Programa de Pós-Graduação em História Social, n.d. 1996, p. 82-117.

49 ELTIS, D. Economic Growth, n. 73, p. 351.

$50<\mathrm{http} / /$ slavevoyages.org/tast/database/search.faces?yearFrom=1830\&yearTo=1866\&ptd epimp $=20600>$.

51 ELTIS, D. Op. cit, p. 158.
} 
um morador em Guadeloupe, foi contratado para trabalhar para Simeon Potter, um importante mercador de Rhode Island. De seus treze filhos, pelo menos sete se tornaram ativos participantes do comércio negreiro na segunda metade do século XVIII ${ }^{52}$.

James D'Wolf se tornou o principal traficante da família e senador dos Estados Unidos por Rhode Island na segunda década do século XIX. Em 1791, no entanto, James foi julgado pelo assassinato de uma escrava. De acordo com John Cranston, um dos marinheiros a bordo do navio, o capitão James lançou uma africana em alto-mar quando retornavam de uma viagem à Costa do Ouro. A testemunha descreve que a escrava estava doente, provavelmente com varíola. Após isolá-la por dois dias, o capitão alertou que a permanência da cativa a bordo colocava em risco a saúde da maioria dos outros escravos e pediu ajuda para se livrar da mesma. John Cranston se negou a ajudar, mas James D'Wolf conseguiu, com a ajuda de outro marinheiro, realizar seu intento. $\mathrm{O}$ processo judicial se arrastou por anos e, ao fim, James foi capaz de escapar das acusações ${ }^{53}$. O fato de que um marinheiro se opôs ao assassinato de uma escrava e veio a público testemunhar contra James D'Wolf, no entanto, demonstra a crescente influência de uma mudança nos valores. Para Marcus Rediker, o caso indica o desenvolvimento de um espírito abolicionista entre marinheiros e outros trabalhadores do $\mathrm{mar}^{54}$. O surgimento de uma nova sensibilidade, no entanto, atravessou classes sociais e criou tensões no interior das próprias elites do Atlântico Norte ${ }^{55}$.

Nos anos seguintes, as atividades de James D'Wolf e seus irmãos foram marcadas por tais tensões. William Ellery, o já mencionado fiscal alfandegário de Newport, denunciou seguidamente as atividades dos D'Wolf após a proibição do tráfico no Estado de Rhode Island. A reação dos traficantes foi temporariamente eficaz. Em 1800, James D'Wolf requisitou a criação de um setor alfandegário especificamente em Bristol, cidade da fa-

52 HOWE, G. Mount Hope: A New England Chronicle. New York: The Viking Press, 1959.

53 "John Cranston's testimony to the Grand Jury, June 15, 1791". Newport Historical Society, Newport, Rhode Island, Caixa 43, Pasta 24.

54 REDIKER, M. The Slave Ship: A Human History. Reprint. Penguin (Non-Classics), 2008, 346.

55 David Geggus argumenta nessa direção em uma análise brilhante acerca do impacto da revolução haitiana. GEGGUS, D. The French and Haitian Revolutions and Resistance to Slavery in the Americas: An Overview. Revue Française d'Histoire d'Outre-Mer, n. 282-283, p. 107-123, 1989. 
mília, até então vinculada à coletoria de Newport. O presidente John Adams acatou o pedido, mas inicialmente nomeou um oficial que procurou fazer valer a legislação abolicionista. Apenas em 1804 os D'Wolf conseguiram nomear um dos seus, Charles Collins, para o cargo de oficial alfandegário do distrito. Collins, também traficante de escravos, permitiu que o comércio negreiro organizado a partir da cidade ocorresse livremente nos anos que se seguiram (Figura 2).

Se por um lado a medida resolveu os problemas provisoriamente, por outro era evidente o isolamento dos traficantes de Rhode Island na pequena cidade de Bristol. Em Newport, Ellery e outras autoridades abolicionistas procuravam fazer valer as leis. Em Providence, o já mencionado

FIGURA 2 - NÚMERO DE ESCRAVOS DESEMBARCADOS NAS AMÉRICAS POR PORTOS DE PARTIDA

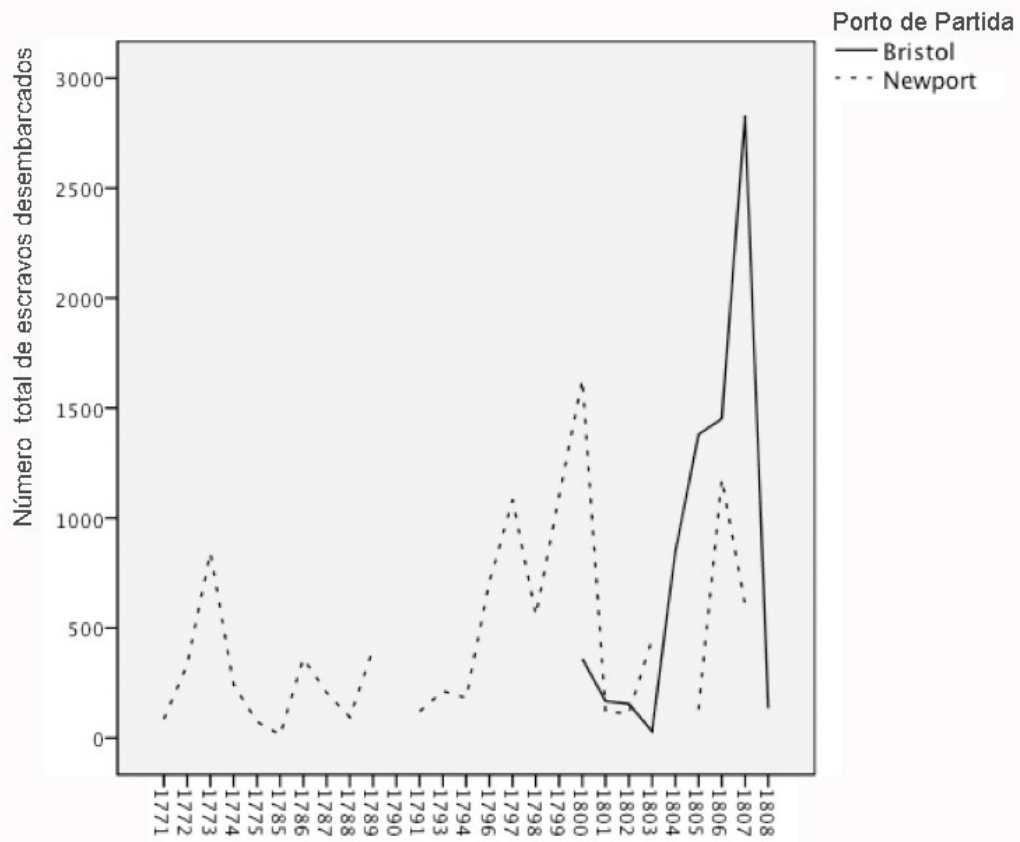

FONTE: cf. Figura 1. 
debate entre os irmãos Brown tomou conta da esfera pública e resultou em uma crescente condenação do tráfico. Tais tensões continuaram a marcar a trajetória de James D'Wolf nos anos que se seguiram.

Durante a primeira década do século XIX, como outros negociantes de New England, os D'Wolf investiram em plantations cubanas. Se o investimento em fazendas em Cuba por um lado atendia a novas oportunidades oferecidas pelo fim de Saint-Domingue, por outro era também um produto da pressão abolicionista. Se o mercado de Havana estivesse saturado ou a Guarda Costeira dos EUA tornasse o contrabando de escravos para o país naquele momento um negócio perigoso, James D'Wolf podia esperar. Como observou George Howe, "ele possuía três fazendas em Cuba - a Mary Ann, a Mount Hope e a Esperanza - onde ele podia guardar seu carregamento até que os preços subissem novamente, como seria o caso mais cedo ou mais tarde" ${ }^{56}$.

James D'Wolf estava, portanto, diretamente interessado no suprimento de africanos para a colônia espanhola e membros da família certamente participaram na organização de viagens negreiras para a ilha após 1807. A questão que permanece em aberto é o volume desse tráfico. Há algumas evidências pontuais. Os recibos da venda do carregamento do navio Arrogancia Castellana enviados a John D'Wolf por seus agentes em Cuba, em 1812, apesar de não descreverem o conteúdo das negociações, estavam possivelmente relacionados ao navio que desembarcou 255 escravos em Havana naquele mesmo ano sob o nome Arrogancia. O capitão era John ou William Munro (o documento apresenta apenas o sobrenome), ambos de Bristol e com longa experiência no tráfico de escravos pré-1808. William Munro chegou mesmo a dividir os custos e ganhos da viagem do navio Jane com James D'Wolf em 1806, que desembarcou 106 escravos também em Havana ${ }^{57}$.

Apesar de ainda conseguirem tirar vantagem do isolamento de Bristol conseguido alguns anos antes, tais atividades ilegais não ocorriam livremente. Três anos mais tarde, o oficial responsável pela fiscalização do porto de Newport, William Ellery, escreveu ao secretário de Estado

56 HOWE, G. Mount Hope, p. 123

$57<\mathrm{http}: / /$ slavevoyages.org/tast/database/search.faces?yearFrom=1514\&yearTo=1866\&voy ageid=14586>; $<$ http://slavevoyages.org/tast/database/search.faces?yearFrom=1514\&yearTo=1866\&vo yageid $=36860>$. 
denunciando possíveis atividades ilegais no distrito de Bristol. "O navio Hermaphrodite, antes conhecido como McDonnough, de Bristol", descrevia Ellery, "foi transformado em um navio espanhol, mas ainda era propriedade de certos negociantes da cidade e estava prestes a navegar para a costa da África com a intenção de lá adquirir escravos”. De acordo com o vigilante do porto de Bristol, "três ou quatro embarcações partiram daquele porto, e ele ouviu que o menor deles chegou em Havana com mais de duzentos escravos". A figura principal por trás das viagens era James D'Wolf, o principal traficante da família. Ellery ainda descreveu como se davam as operações ilegais:

Uma nota fiscal da embarcação é feita pelo proprietário ou proprietários para um estrangeiro e ao mesmo é fornecido dinheiro para adquirir o carregamento apropriado para o comércio, e antes da saída do navio o estrangeiro devolve o navio e o carregamento para os donos americanos. É fácil para o coletor distrital onde tal comércio ocorre reconhecer os vendedores e compradores originais, mas é extremamente difícil de provar a devolução como vem sendo feita e eu mencionei ${ }^{58}$.

Os D'Wolf, portanto, estiveram envolvidos no tráfico de escravos durante a década de 1810 e não apenas como proprietários de viagens escravas. Em 1810, a Companhia de Seguros de Bristol segurou uma viagem à África do navio espanhol Francisco de Assis, de propriedade de Truman Mayberry, cobrindo "o perigo dos mares, de fogo e inimigos", mas excluindo "a mortalidade de escravos", o que documentava a ilegalidade da empreitada. A Companhia de Seguros de Bristol, fundada em 1800 e dirigida pelos D'Wolf, foi, provavelmente, a principal seguradora de viagens escravas em Rhode Island, senão nos Estados Unidos, entre 1800 e $1807^{59}$. A viagem do Francisco de Assis, no entanto, é a única com destino à África no livro de seguros da Companhia de 1810-1812. A maioria das viagens seguradas no livro foi para Cuba, que vinha se tornando um dos principais parceiros comerciais dos Estados Unidos.

58 Carta de William Ellery, Stockbridge Library, Sedgwick Papers, Dezembro 1815.

59 Record of Policy Mt Hope Insurance Co. - 1810-1812 for ships, Bristol Historical Preservation Society, John D'Wolf Papers. 
Os D'Wolf aparentemente não tiveram grandes prejuízos com a abolição do tráfico, apesar de continuarem envolvidos com o mesmo durante o período ilegal. A família diversificou suas atividades, investindo em outras áreas - como a indústria têxtil de Rhode Island, as já citadas plantações de café e açúcar em Cuba, e corso. James D’Wolf possuía uma das maiores fortunas de Rhode Island quando veio a falecer em fins da década de 1830 . Seu testamento listava companhias de manufatura de algodão, navios empregados na pesca baleeira, títulos no Banco de Bristol, duas fábricas têxteis, terras e propriedades em Rhode Island, Massachusetts, Nova Iorque, Kentucky, Baltimore e as já mencionadas plantações cubanas, com todos os seus escravos, café e açúcar ${ }^{60}$. Não há, no entanto, qualquer referência ao tráfico. Se na década de 1810 evidências de participação dos D'Wolf eram escassas, na década seguinte elas desapareceram.

Ainda assim as tensões geradas pelos anos do tráfico continuavam a marcar a vida de James D'Wolf. Seu irmão Levi D'Wolf se envolveu com os Quakers de Rhode Island, como havia feito Moses Brown poucos anos antes. Em 1821, James escreveu para seu irmão John que o envolvimento “do irmão Levi com os Quakers não fará bem a ele". Segundo James, "os Quakers e a sociedade abolicionista fizeram uso de todos os meios e estratégias possíveis para evitar minha eleição". Ele havia sido eleito senador dos Estados Unidos, um processo que, segundo ele, representava "os sentimentos populares de R.I. [Rhode Island]" ${ }^{\prime \prime}$. Apesar do comentário confiante, a trajetória de James D'Wolf demonstrava a persistência de tensões que se iniciaram em fins do século XVIII e o perseguiram até o fim de sua vida.

Estava claro para traficantes de Rhode Island que a região havia adentrado um novo espaço ideológico que tomou conta do mundo anglo-americano a partir de fins do século XVIII. James D'Wolf foi capaz de manter suas fazendas com escravos em Cuba, mas não de continuar seu envolvimento no tráfico atlântico de escravos. A participação dos EUA no tráfico de modo geral se tornou mais difusa e colocou novos desafios às autoridades abolicionistas nas décadas que se seguiram. Se na primeira década após 1807 o problema havia sido a presença de americanos e britânicos, como James D’Wolf, operando o tráfico sob a bandeira espanhola,

60 Testamento de James D'Wolf. Bristol Town Hall.

61 James D'Wolf to John D'Wolf, Washington D.C., 21 Dec. 1821, BHPS. 
tal correlação parece ter se invertido nas décadas finais do tráfico. Há uma diferença significativa nas características da participação americana nos dois períodos, transitando do financiamento direto de viagens para o uso da bandeira, documentos, navios e tripulantes norte-americanos por outras nações. Traficantes como os D'Wolf desapareceram em meados do século XIX. Os poucos casos de investimento direto de americanos parecem ter sido relacionados ao debate de reabertura do tráfico para o sul na década de 1850 , e mesmo esses parecem ter sido excepcionais. As tensões que passaram a permear o norte dos EUA após o desenvolvimento de um novo ambiente de condenação ao tráfico marcaram, como visto, a trajetória dos maiores traficantes de escravos da história dos Estados Unidos. O fim da rede de Rhode Island marcou, por sua vez, uma transformação na natureza do envolvimento norte-americano. As articulações geradas por esse novo espaço antiescravista ao norte do Atlântico são fundamentais para que compreendamos as formas do tráfico ilegal oitocentista e as dinâmicas de sua supressão.

Recebido em 09/11/2009. Aprovado em 15/12/2009. 